Revista Española de

I n v e stig a c íón

Criminológ i ca

\title{
El perfil geográfico de la delincuencia juvenil: Un análisis de las características espaciales asociadas a la movilidad delictiva de los jóvenes
}

\section{The geographic profile of juvenile delinquency: An analysis of the spatial characteristics associated with youth criminal mobility}

David Vázquez

Universidad de Castilla-La Mancha

Esther Fernández ${ }^{1}$

Universidad de Castilla-La Mancha

Simón Planells-Struse

Universidad de Barcelona

Mario Belmonte

Universidad de Castilla-La Mancha

Artículo recibido el 16 julio 2014/Publicado el 16 de diciembre de 2014

\section{RESUMEN}

La relación entre espacio y delincuencia ha sido ampliamente documentada por los criminólogos ambientales. En España, dada la escasez de datos cuantitativos, el conocimiento que se tiene aún es limitado y se hace preciso un mayor desarrollo de investigación empírica, más si cabe en lo referido a la delincuencia juvenil. Con objeto

\footnotetext{
${ }^{1}$ La correspondencia debe enviarse a Esther Fernández Molina. Centro de Investigación en Criminología, Universidad de Castilla-La Mancha. Edificio Benjamín Palencia, Campus Universitario, s/n, CP: 02071, Albacete (España). E-mail: esther.fdez@uclm.es
} 
de profundizar en el conocimiento acerca de las características espaciales de la delincuencia juvenil, utilizando una muestra de 145 casos extraídos de las diligencias incoadas en 2009 por la Fiscalía provincial de menores de Albacete, el presente estudio lleva a cabo un análisis exploratorio en dos etapas. En la primera etapa, se analiza la distribución espacial del fenómeno por medio de la elaboración y visualización de mapas de hotspots. Seguidamente, para ahondar en los determinantes del desplazamiento de estos delincuentes hasta los lugares donde delinquen, se lleva a cabo un análisis de regresión utilizando algunas de las variables que la literatura especializada ha considerado más significativas.

Palabras clave. Criminología ambiental, delincuencia juvenil, puntos calientes, Sistemas de Información Geográfica (SIG), trayecto al lugar del delito.

\begin{abstract}
The relationship between space and crime has been broadly analyzed by environmental criminologist. In Spain, given the lack of quantitative data, the knowledge on the topic is limited and makes it necessary to increase empirical research, especially in the field of juvenile delinquency. The present research uses a sample of 145 cases obtained from the regional court of Albacete in order to deepen the knowledge on the spatial characteristics of juvenile delinquency. The study carries out and exploratory data analysis (ESDA) in two stages. In the first stage, we analyze the spatial distribution of the juvenile crimes and residence of offenders by mapping the hotspots. Afterwards, in order to deepen on the determinants of the displacement of juvenile offenders from their homes to the spot where they commit their offences we carry out a confirmatory analysis by mean of regressions using the variables that the literature points out to be important.
\end{abstract}

Keywords. Environmental criminology, juvenile delinquency, hotspots, Geographic Information Systems (GIS), journey to crime.

\title{
1. Introducción
}

La delincuencia posee un importante componente geográfico, pues la mayor parte de los delitos ocurren en momentos y lugares concretos, y los perpetran personas que vienen o van a algún lugar o se encuentran en un determinado sitio (Dávila y Ponce, 1998). Sin embargo, es relativamente reciente el interés de la Criminología por la dimensión espacial de la delincuencia.

A lo largo de las últimas décadas la producción de un gran volumen de literatura científica enmarcada en la categoría de criminología ambiental ha permitido reconocer que la comprensión del delito mejora si se tiene en cuenta cómo las características del escenario ayudan a convertir las inclinaciones delictivas en acción (Felson y Clarke, 
1998). A este respecto, se sabe que el delito no es un fenómeno que se distribuya aleatoriamente en el espacio o el tiempo, sino que muestra patrones de agrupación distintivos y previsibles conocidos como hotspots en el mundo anglosajón. Mientras que algunos lugares apenas registran sucesos delictivos, en otros se acumulan los incidentes. Si además se tiene en cuenta la variable temporal, se observa que los patrones espaciales pueden experimentar variaciones en el tiempo (Ocáriz, Vozmediano y Germán, 2011).

Atendiendo a lo señalado por Felson y Clarke (1998) la concentración de mayores oportunidades delictivas en lugares y en momentos concretos, y por tanto la concentración de incidentes, puede deberse a factores como: un mayor número de delincuentes en la zona, un bajo nivel de vigilancia formal o informal que ayuda a los delincuentes a ser más eficientes en su labor, o una alta concentración de objetivos atractivos lo cual incita a más personas a delinquir.

Sabiendo dónde sucede y se concentra el delito, una de las cuestiones que se han planteado los investigadores es cómo y por qué confluyen en dichos puntos víctimas y delincuentes. Prestando atención a las características del trayecto recorrido por los infractores hasta el lugar del suceso, es posible saber si los delitos tienden a ocurrir en torno a los lugares donde residen y pasan gran parte de su tiempo, o en zonas más alejadas de su cotidianeidad, lo cual supone un paso importante en la comprensión de las dinámicas delictivas pues informa acerca de cuestiones tales como el grado de planificación de los delitos.

Sin embargo la evidencia empírica que se tiene en España respecto a las características espaciales de la movilidad delincuencial aún es limitada, pues tal y como apuntan Vozmediano y San Juan (2010) la producción científica nacional enmarcada en la categoría de criminología ambiental, además de ser reducida y relativamente reciente, se ha centrado principalmente en la representación y análisis de los puntos calientes de concentración delictiva (hotspots) o en el desarrollo de técnicas de prevención situacional.

En el caso de la delincuencia juvenil, que por sus características es más sensible a la influencia de los factores ambientales (Irene, 2010), la evidencia es mucho más reducida si cabe. Una mejor comprensión de cómo las características espaciales determinan las oportunidades delictivas y el comportamiento infractor de los jóvenes resulta de gran ayuda en los esfuerzos preventivos, pues permite formular estrategias de 
alteración de las oportunidades delictivas basadas en la evidencia científica, en lugares específicos (Law y Quick, 2013).

Por todo ello, con objeto de aumentar el conocimiento que se tiene respecto al comportamiento espacial de la delincuencia juvenil, el presente trabajo analiza algunos factores relacionados con la movilidad de los jóvenes delincuentes combinando elementos de diversas perspectivas teóricas utilizadas por la criminología ambiental. Este tipo de análisis permite una mejor comprensión de los espacios de actividad y las actividades de rutina de los menores infractores, lo cual resulta de gran utilidad a la hora de llevar a cabo estrategias de intervención y prevención. El éxito y la implementación de este tipo de estrategias situacionales dependen en gran medida del conocimiento que las autoridades locales tengan de las dinámicas espaciales de este tipo de delincuencia. Por ejemplo, un lugar con alta concentración delictiva, no requiere las mismas medidas si los delincuentes viven en el barrio o si se han desplazado hasta allí.

\section{1. ¿Cómo se ha explicado el desplazamiento de los delincuentes?}

El enfoque de las actividades rutinarias, desarrollado en 1979 por Cohen y Felson, se ha consagrado a explicar cómo los patrones de comportamiento de una sociedad afectan a las oportunidades delictivas, en la medida en que la organización social y las rutinas de la vida diaria hacen que la convergencia de delincuentes motivados y objetivos adecuados sea más o menos probable (Drawvea, Walkera y Felson, 2014; Groff, 2005; Vozmediano y San Juan, 2010). Según estos autores, cuando hay cambios en estos patrones de comportamiento, las oportunidades delictivas también cambian.

La teoría sitúa los eventos delictivos en el contexto de otra serie de actividades cotidianas no delictivas como puede ser ir al trabajo, a la escuela, a la compra, a la estación de metro, a un centro comercial o a un bar de copas, donde el delincuente encuentra sus objetivos cerca de su entorno habitual, en su espacio de conciencia (Groff, 2005; Schaefer, 2012).Cuando estos lugares carecen de vigilancia efectiva, combinan las cualidades que son deseables para los delincuentes y la probabilidad de que un hecho delictivo ocurra, aumenta sustancialmente (Cohen y Felson, 1979).

La perspectiva de las actividades rutinarias sugiere que la oportunidad delictiva puede existir en cualquier lugar dentro del espacio de conciencia del delincuente, sin 
embargo, éste no elige el lugar del delito al azar. Para conocer cómo operan los delincuentes dentro de su espacio de conciencia es especialmente relevante otra teoría, la del patrón delictivo (Kent, Leitner y Curtis, 2006).

El trabajo pionero de Brantingham y Brantingham (1991), en concreto el desarrollo de la teoría del patrón delictivo, es clave para entender cómo se mueven en el espacio y el tiempo los actores involucrados en un delito. Coincidiendo con el enfoque de la actividad rutinaria sugiere que los patrones de movimiento de los delincuentes son iguales a los de cualquier otra persona, lo que facilita la convergencia espacio-temporal de delincuentes y víctimas.

En contraste con el enfoque de las actividades rutinarias, la teoría del patrón delictivo no afirma explícitamente que los delitos tengan lugar durante las rutinas diarias habituales, se limita a señalar que los delincuentes aprenden sobre su entorno durante esas rutinas. Las rutas o trayectos que el delincuente realiza de forma regular para desplazarse entre sus nodos ${ }^{2}$ de actividad rutinaria, determinan lo que conoce y aprende de su ciudad, y por tanto también donde busca y encuentra objetivos (Brantingham y Brantingham, 1995). Concretamente, el conocimiento de las zonas donde desarrolla sus actividades cotidianas le permite identificar aquellas características ambientales más favorables para que se produzca el delito, pudiendo seleccionar sus objetivos en aquellos lugares en los que se siente más cómodo (Brantingham y Brantingham, 1993).

Por lo tanto, el delito sucede dónde y cuándo ese espacio de conciencia del delincuente se cruza con oportunidades delictivas (Bernasco, 2014), y algunos lugares ofrecen mayores oportunidades delictivas que otros. En este sentido, los Brantingham (1995) señalan que la concentración delictiva en zonas determinadas está relacionada con la existencia de tres tipos de ambientes: generadores, atrayentes, y neutros.

Son consideradas generadoras de delincuencia aquellas áreas que congregan a un gran número de personas atraídas por razones ajenas a cualquier motivación delictiva, como por ejemplo las zonas comerciales, de ocio, oficinas, centros educativos, transporte público, etc., pudiendo serlo sólo en ciertos momentos temporales (fines de semana, de noche, hora punta, etc.). En este caso las oportunidades delictivas surgen en

\footnotetext{
${ }^{2}$ Son aquellos lugares donde las personas realizan regularmente actividades cotidianas, como el hogar, centro educativo, casas de amigos y familiares, zonas de ocio, etc. (Brantingham y Brantingham, 1993).
} 
lugares y momentos que proporcionan concentraciones de personas u otros objetivos en ambientes que favorecen determinados tipos de actos delictivos. Entonces, individuos que a priori no habían acudido a esos lugares con la intención expresa de delinquir al encontrarse con oportunidades tentadoras favorecidas por el ambiente deciden actuar.

Son atrayentes de la delincuencia aquellos lugares, áreas, barrios, etc. que atraen delincuentes motivados con la intención expresa de delinquir porque conocen la existencia de oportunidades para la realización de ciertos tipos de delitos. Por ejemplo, zonas de pubs donde se acude con la motivación de buscar pelea, barrios donde se trafica con droga para comprar o vender, parkings con una baja vigilancia donde robar piezas de los coches, o centros comerciales con bajas medidas de seguridad para cometer hurtos. Los delitos en estos lugares por lo general son cometidos por personas de otras zonas que se desplazan en busca de oportunidades concretas. Cuando son perpetrados por residentes pueden ser personas que previamente se habían desplazado a vivir a esa zona debido a sus cualidades atrayentes del delito, o porque como sucede en muchas ciudades, los barrios pobres están situados cerca de zonas comerciales con muchos objetivos cerca de su casa (Brantingham y Brantingham, 1995).

Son áreas neutras en relación con la delincuencia aquellas que no cumplen las características de las anteriores, en las que el delito ocurre de manera muy esporádica y generalmente perpetrado por personas residentes en la zona.

Sin embargo, conviene puntualizar que no es habitual la existencia de áreas puramente generadoras, atrayentes o neutras. La mayor parte suelen ser mixtas en el sentido de que pueden ser atrayentes, generadoras o neutras dependiendo el tipo de delito (Brantingham y Brantingham, 1995).

\section{2. ¿Qué sabemos acerca del desplazamiento de los delincuentes?}

La convergencia espacio-temporal de delincuentes y objetivos, a excepción de los delitos que ocurren en el propio hogar, implica un desplazamiento por parte del infractor, denominado journey to crime en la literatura anglosajona. En el análisis del journey to crime o trayecto al lugar del delito, son relevantes aspectos como la motivación del delincuente, el origen, el destino, la ubicación del delito, la ruta que 
toma, el momento temporal, la duración, la distancia, la dirección, el modo de desplazarse y si lo hace solo o en compañía de otras personas (Bernasco, 2014).

Sin embargo, tal y como apuntan Andresen, Frank y Felson (2014) o Townsley y Sidebottom (2010) debido principalmente a la dificultad de obtener información más completa que la incluida en los registros policiales, la mayor parte de la literatura se ha centrado exclusivamente en la distancia. Un hallazgo compartido es que la distancia recorrida por los delincuentes es generalmente corta, especialmente para delitos violentos (Andresen, Frank y Felson, 2013; Levine y Lee, 2009; Phillips, 1980; Wiles y Costello, 2000).

La principal explicación al respecto, con base en los enfoques de la actividad rutinaria y del patrón delictivo, es que la eficiencia delictiva se maximiza y los costos del desplazamiento se reducen cerca de donde los delincuentes desarrollan cotidianamente sus actividades (Block, Galary y Brice, 2007). Cuando el área cercana a estos puntos no ofrece oportunidades, los costos y riesgos del desplazamiento aumentan, por ello en la medida de lo posible los delincuentes tratan de cometer la mayor parte de sus delitos lo más cerca que puedan de su zona para minimizar ese costo (Van Patten, McKeldin-Coner y Cox, 2009). Conforme aumenta la distancia, disminuye la frecuencia de sucesos delictivos, lo que es conocido por el término anglosajón distance decay (Bernasco, 2014).

Sin embargo, tal y como señala Felson (2006), algunos delincuentes buscan los objetivos más lejos y se desplazan mayores distancias si el beneficio que se deriva de la comisión del delito es cuantioso. Esto, se ha interpretado en términos de la disyuntiva entre costos y beneficios esperados. Si el delincuente espera una gran recompensa encontrará justificado incurrir en mayores costos para alcanzar su objetivo (Bernasco, 2014). Un ejemplo es el robo de bancos, pues el delincuente está dispuesto a viajar una gran distancia para alcanzar una buena meta (Block, Galary y Brice, 2007). Por lo general, un mayor desplazamiento suele reflejar una mayor nivel de planificación y selectividad en el proceso de comisión del delito (Cornish y Clarke, 2008).

Otro concepto empleado habitualmente por la criminología ambiental, denominado buffer zone o zona de seguridad, hace referencia al área o perímetro que rodea los principales nodos de actividad del delincuente, especialmente su casa, donde 
se ha constatado que no actúa por temor a ser reconocido (Block, Galary y Brice, 2007; Kent, Leitner y Curtis, 2006; Vozmediano y San Juan, 2010).

La distancia recorrida hasta el lugar del delito en la mayor parte de investigaciones oscila entre 1.609,3 metros (1 milla) y 3.218,7 metros (2 millas) (Clarke y Eck, 2005). No obstante, dicha distancia ha mostrado estar condicionada por características relacionadas tanto con el delito, como es la tipología delictiva (los delitos contra la persona suelen producir desplazamientos más cortos que los delitos contra el patrimonio), como con el delincuente, como es la edad (los menores suelen recorrer distancias más cortas que los adultos) (Townsley y Sidebottom, 2010).

Por lo general, los patrones de movimiento de los jóvenes están restringidos a lugares más concretos, pues poseen un mapa cognitivo aún limitado (Snook, 2004). A medida que el sujeto va creciendo estas pautas van cambiando al igual que las rutinas, lo cual conlleva diferentes distancias también cuando se cometen delitos (Drawve, Walkera y Felson, 2014). Sin embargo, a diferencia de la cuantiosa literatura existente respecto a la distancia recorrida hasta el lugar del delito por delincuentes adultos, los estudios específicos sobre delincuentes juveniles son más escasos.

\subsection{El comportamiento espacial de la delincuencia juvenil}

Las teorías del delito basadas en el aprendizaje o en el control social sugieren que la delincuencia juvenil se encuentra condicionada por los factores ambientales en mayor medida que la delincuencia adulta. Esto parece ser así porque la adolescencia se caracteriza por ser una etapa vital en la que el individuo es más sensible a la influencia de otras personas, como pueden ser otros delincuentes residentes en el barrio, y además precisa el apoyo de un mayor control social informal comunitario (Irene, 2010). Aquellas áreas o barrios que presentan una alta desorganización social ${ }^{3}$ son más propensas a exhibir mayores tasas de delincuencia juvenil, pues la escasa cohesión social y la carencia de objetivos comunes conduce un control social informal limitado y poco efectivo que no garantiza una correcta supervisión del comportamiento de los jóvenes (Law y Quick, 2013).

\footnotetext{
${ }^{3}$ Según la teoría de la desorganización social son aquellas con un alto grado de desintegración familiar, privaciones sociales y económicas, heterogeneidad étnica y la rotación de la población itinerante (Law y Quick, 2013).
} 
Por ello, la influencia del ambiente en el que viven y se socializan los menores ha revelado ser importante, pues a pesar de existir otros muchos factores de riesgo que pueden llevar al sujeto a cometer delitos independientemente del contexto socioeconómico de su barrio, aquellos con menos factores de riesgo individuales tienen más probabilidades de convertirse en delincuentes cuando viven en zonas socialmente desfavorecidas (Wikström y Loeber, 2000).

Se sabe que las actividades rutinarias que realizan los menores están concentradas en lugares específicos, en parte debido a las restricciones impuestas por cuestiones como la obligación de asistir diariamente a sus centros educativos o el limitado acceso al uso de vehículos a motor (Weisburd, Morris y Groff, 2009). La literatura señala dos áreas principales donde los jóvenes pasan la mayor parte del tiempo, el hogar y el centro educativo. Por tanto, es en estos dos nodos de actividad, en sus inmediaciones o en el camino entre ellos donde surgen la mayor parte de oportunidades delictivas (Drawve, Walkera y Felson, 2014; Weisburd, Morris y Groff, 2009). En este sentido, Jacob y Lefgren (2003) encontraron que los delitos violentos aumentaban considerablemente los días que los menores tenían clase, concretamente a las 15.00 horas, coincidiendo con la salida de los centros escolares. En cambio los delitos contra la propiedad perpetrados por jóvenes se reducían a esas horas siendo más comunes en horario de tarde o en periodos vacacionales.

Así mismo, las zonas que concentran altos niveles de delincuencia juvenil también suelen contener otros nodos de actividad juvenil con alto magnetismo como centros comerciales, tiendas, cines, restaurantes de comida rápida, bares, etc. (Drawve, Walkera y Felson, 2014; Groff, 2005; Weisburd, Morris y Groff, 2009). Concretamente, la delincuencia juvenil está fuertemente asociada a lugares y actividades de ocio que implican la relación entre iguales en ausencia de figuras de autoridad. El hecho de que los jóvenes son más propensos a victimizar a otros menores refuerza la importancia de este tipo de espacios en el desarrollo de la delincuencia juvenil (Weisburd, Morris y Groff, 2009).

Tradicionalmente la juventud ha sido relacionada con una menor distancia recorrida (Phillips, 1980; Snook, 2004; Wiles y Costello, 2000), lo que principalmente se ha atribuido a un menor acceso a vehículos motorizados. Sin embargo, recientemente Andresen, Frank y Felson (2014) han cuestionado la existencia de una relación lineal 
positiva entre las variables edad y distancia, al hallar que la distancia cuando se cometían hechos delictivos aumentaba hasta los 20 años y luego volvía a disminuir progresivamente. Amparándose en la naturaleza dinámica de las actividades de rutina, estos autores justifican que dicha relación en forma de $U$ invertida podría deberse a la necesidad de escapar de la vigilancia de padres y tutores experimentada durante la adolescencia que lleva a los sujetos a desplazarse más lejos de lo necesario para realizar sus actividades. A medida que las personas van siendo adultas dejan de sentir dicha necesidad y suelen disponer de un menor tiempo libre, por lo cual prefieren recorrer distancias más cortas.

No obstante, cuando sólo se tiene en cuenta a los menores, como el estudio realizado por Drawve, Walker y Felson (2014) quienes analizan una muestra de individuos entre 11 y 17 años, la relación parece ser lineal y positiva. La distancia aumenta progresivamente desde los 2890,4 metros a los 12 años (1,7960 millas) a los $3.515,1$ metros a los 17 años (2,1842 millas).

Al igual que en el caso de los adultos, se ha observado que las variaciones en la distancia recorrida se encuentran relacionadas con otros factores, como el género, la tipología delictiva, la influencia del grupo de pares y el acceso a vehículos de motor (Bichler, Christie-Merall y Sechrest, 2011). En este sentido, se sabe que los delitos contra el patrimonio conllevan distancias más largas que los delitos contra la persona (Drawve, Walkera y Felson, 2014), las chicas se desplazan más lejos que los chicos para delinquir en el centro de la ciudad y zonas comerciales (Levine y Lee, 2009), y con pocas excepciones, los jóvenes que utilizan vehículos a motor realizan desplazamientos más largos cuando cometen delitos, diferencia que aumenta a medida que también lo hace la edad (Bichler, Christie-Merall y Sechrest, 2011; Snook, 2004).

\section{Objetivos}

El propósito de este trabajo es identificar pautas espacio-temporales asociadas a la movilidad delictiva de los infractores juveniles. Para ello, se plantean dos objetivos interrelacionados:

- En un primer momento, analizar la distribución espacial de los hechos delictivos cometidos por los delincuentes juveniles, así como de los lugares de residencia de 
estos menores, identificando la existencia de patrones de agrupación y la relación entre estos.

- Seguidamente, analizar el cariz de los desplazamientos realizados por estos delincuentes juveniles, atendiendo a la relación entre la distancia recorrida desde su casa hasta el lugar del suceso y algunas variables relevantes relacionadas tanto con el hecho delictivo como con el delincuente.

\section{Metodología}

\subsection{Datos y área de estudio}

Los datos pertenecen a una investigación más amplia realizada en la Fiscalía provincial de menores de Albacete en la cual se analizó el 20\% de las diligencias incoadas en 2009 (245). Esta información fue extraída y sistematizada utilizando un instrumento diseñado ad hoc. De esas diligencias se identificaron los casos que se produjeron en la localidad de Albacete resultando un total de 154. En la medida que en nueve casos no figuraba la dirección del lugar de la comisión de los hechos, lo que hacía imposible georreferenciar la información, fueron excluidos del análisis quedando la muestra final compuesta por 145.

Albacete es una ciudad situada al Sureste de España, capital de provincia en la comunidad autónoma de Castilla-La Mancha, con una extensión de $1.234 \mathrm{~km}^{24}$. Según los datos del Padrón Municipal de Habitantes (INE) constituía el término municipal más poblado de Castilla-La Mancha durante 2009 con 169.716 habitantes.

\subsection{Materiales y tratamiento de los datos}

La georreferenciación de los datos referidos tanto al lugar de residencia de los delincuentes juveniles (origen) como al lugar de comisión de los hechos delictivos (destino) se efectuó utilizando la herramienta Geocoding ${ }^{5}$, obteniendo dos ficheros en

\footnotetext{
${ }^{4}$ Diputación Provincial de Albacete. Disponible en: http://www.dipualba.es/municipios/habitantes.htm

${ }^{5}$ Geocoding es una aplicación desarrollada por el IDR UCLM - TERYSOS basada en la automatización de llamadas al API de codificación geográfica de Google, permitiendo la obtención de las coordenadas geográficas de direcciones físicas. Está disponible en: http://161.67.130.147/geocoding/
} 
formato CSV, uno para el origen y otra para el destino. A posteriori, estos ficheros CSV se convirtieron al formato Shape utilizando el software libre gvSIG, reproyectando el sistema de coordenadas a ETRS 89.

El tratamiento y procesado de tablas alfanuméricas se llevó a cabo utilizando el programa ArcView, con el que también se realizó el cálculo de la distancia entre la dirección de origen y la de destino mediante la función distancia euclidiana, generando una nueva variable con la distancia recorrida por cada delincuente de la muestra.

El procesamiento y tratamiento estadístico de los datos se realizó utilizando el programa IBM-SPSS-Statistics@, en su versión 19.0. Por su parte, la elaboración de los mapas así como de las funciones de densidad de Kernel, se llevó a cabo con la ayuda del software Arcmap@ en su versión avanzada, combinando las capas de origen y destino con el callejero de libre acceso Open Street Maps@.

\subsection{Estrategia analítica}

Con el objetivo de analizar los patrones de desplazamiento de los jóvenes delincuentes desde sus lugares de residencia hasta el punto donde se cometen los hechos delictivos, en concordancia con los objetivos planteados se efectuó un análisis en dos etapas.

En una primera etapa se llevó a cabo un análisis exploratorio de datos espaciales a través de análisis descriptivos y pruebas de significación, así como la elaboración y visualización de mapas que muestran los lugares donde se ubican la residencia de los delincuentes juveniles (origen) y las zonas donde se concentran los hechos delictivos cometidos por estos (destino).

A posteriori, la segunda etapa del análisis consistió en un análisis de regresión lineal múltiple. Para introducir las variables independientes se optó por el método de pasos sucesivos, donde la variable dependiente es la distancia recorrida desde el hogar del delincuente hasta el lugar de comisión del hecho delictivo en metros, y las variables independientes están agrupadas en las siguientes categorías ${ }^{6}$ :

\footnotetext{
${ }^{6}$ Las palabras en cursiva reflejan las diferentes categorías de cada variable las cuales, se han introducido en forma de variables dicótomas que toman valor 1 si la variable cumple el criterio, y 0 de lo contrario, en todo caso se ha dejado una categoría de referencia.
} 
- Naturaleza del hecho delictivo: Las categorías de análisis empleadas se corresponden con las conductas delictivas que las leyes penales españolas recogen como hechos típicos. No obstante, dado el reducido tamaño de la muestra, para mejorar la capacidad explicativa del análisis se han agrupado las diferentes tipologías delictivas en: hechos delictivos contra el patrimonio y hechos delictivos contra las personas. En el modelo de regresión se añade una variable dicótoma con valor 1 si es un hecho delictivo contra el patrimonio y valor 0 en caso contrario.

- Gravedad del hecho imputado: En concreto se distinguieron si fueron: faltas o delitos. En el modelo de regresión se añade una variable dicótoma que toma valor 1 para los delitos y 0 en caso contrario.

- Sexo: En el modelo de regresión se añade una variable dicótoma que toma valor 1 para los hombres y 0 para las mujeres.

- Edad: se refleja la edad del delincuente en años.

- Hora: Se han agrupado las horas diferenciando entre tres franjas horarias: Mañana (08:00 - 15:59 hs.), tarde (16:00 - 23:59 hs.) y noche (00:00 - 07:59 hs.). Para cada hora se ha creado una variable dicótoma que toma valor 1 cuando el hecho delictivo se ha cometido en la franja horaria de referencia y 0 de lo contrario. Para evitar la trampa de la variable dicótoma ${ }^{7}$ y no caer en un problema de multicolinealidad perfecta, se ha tomado como hora de referencia el horario de noche.

- Nacionalidad: En el modelo de regresión se añade una variable que toma valor 1 para los delincuentes de nacionalidad española y 0 si son extranjeros.

- Solo o en compañía: Variable que permite discernir si el hecho delictivo se cometió sólo, acompañado de un adulto o de otros menores, diferenciando entre estas tres posibilidades. En el modelo de regresión se añade una variable dicótoma que toma valor 1 si el delincuente va acompañado de otro joven y 0 en caso contrario.

- Tipo de perjudicado: Se identifica quién fue la víctima del hecho delictivo diferenciando si se trata de una persona física o una persona jurídica como por ejemplo un establecimiento comercial o entidad. En el modelo de regresión se introduce una variable dicótoma que toma valor 1 cuando se trata de una persona física y 0 cuando se trata de una persona jurídica.

\footnotetext{
${ }^{7}$ Este problema surge de incluir una variable dicótoma para valor cualitativo de una variable. Para evitarlo, cabe dejar una de las categorías con valor 0 .
} 
- Lugar del hecho delictivo: Se ha diferenciado si el hecho delictivo se cometió en vía pública, domicilio, establecimiento comercial o colegio. En el modelo de regresión, estas variables se introducen de forma dicótoma y toman valor 1 cuando se dan en cada uno de los lugares y 0 cuando el hecho delictivo se da en un establecimiento comercial.

\section{Resultados}

\subsection{Análisis descriptivo}

En relación con las características de los delincuentes, se observa que la mayoría de ellos son varones con una edad media de 16 años, de nacionalidad española. En cuanto a las características del hecho delictivo, aquellos que se cometen contra el patrimonio representan cerca de un $62 \%$, mientras que los que atentan contra las personas engloban un $25 \%$. Atendiendo a la franja horaria de comisión del hecho delictivo, durante la tarde se producen un $34 \%$, en las horas de la mañana casi un 30\%, y el porcentaje más alto ocurre durante las horas nocturnas. En relación con el lugar de comisión de los ilícitos, la vía pública es el lugar predominante. En su mayoría hurtos que se producen en las calles, en especial en las calles céntricas de la ciudad. Los robos parecen ser más comunes en los domicilios particulares o en los establecimientos comerciales mientras que los hechos delictivos cometidos en colegios, parecen ser minoritarios y fundamentalmente son sucesos violentos. La delincuencia juvenil por lo general está caracterizada por llevarse a cabo en grupo como así lo confirman también nuestros datos. Un $47 \%$ de los hechos delictivos se ha producido de forma conjunta con otros menores mientras que un $11 \%$ de forma conjunta con una persona adulta.

\subsection{Análisis exploratorio de los datos espaciales}

El mapa 1 muestra de manera conjunta la distribución de los hechos delictivos así como la distribución de la residencia de los jóvenes delincuentes. Las figuras con forma de casa representan la localización exacta de la residencia de los delincuentes. En lo que se refiere a las infracciones cometidas por los jóvenes, para facilitar la comprensión se han 
representado utilizando las funciones de densidad Kernel. Estas funciones estiman para cada unidad espacial, una estimación de la magnitud del número de hechos delictivos teniendo en cuenta, no sólo los hechos delictivos de la propia unidad espacial, sino también de los hechos delictivos que tienen lugar en un radio determinado. El resultado es una representación más suave en el espacio que la realizada puramente con los datos de punto y que permite una mejor visualización de patrones de concentración delictiva. Su interpretación es una estimación del número de hechos delictivos por $\mathrm{km}^{2}$.

En nuestra representación concreta, para mostrar el resultado con detalle, se ha elegido una unidad espacial en forma de celda cuadrada de 20 metros de longitud ${ }^{8}$. Además, se han considerado como unidades espaciales vecinas todos aquellos hechos delictivos que caen en el radio de 200 metros. De esta forma, se refleja un cierto efecto contagio de la actividad delictiva que ocurre en mayor medida entre jóvenes y se consigue una representación de la distribución de los hechos delictivos más intuitiva. Aquellas áreas rojas con un color más intenso reflejan un mayor número de delitos y faltas por $\mathrm{km}^{2}$, mientras que aquellas áreas azules con menor densidad reflejan un nivel menor.

\footnotetext{
${ }^{8}$ Cabe decir que el tamaño de la celda, según la literatura, parece no ser un factor determinante de los valores estimados (Waller y Gotway, 2004).
} 
Mapa 1. Residencia de los jóvenes delincuentes y funciones de densidad de Kernel

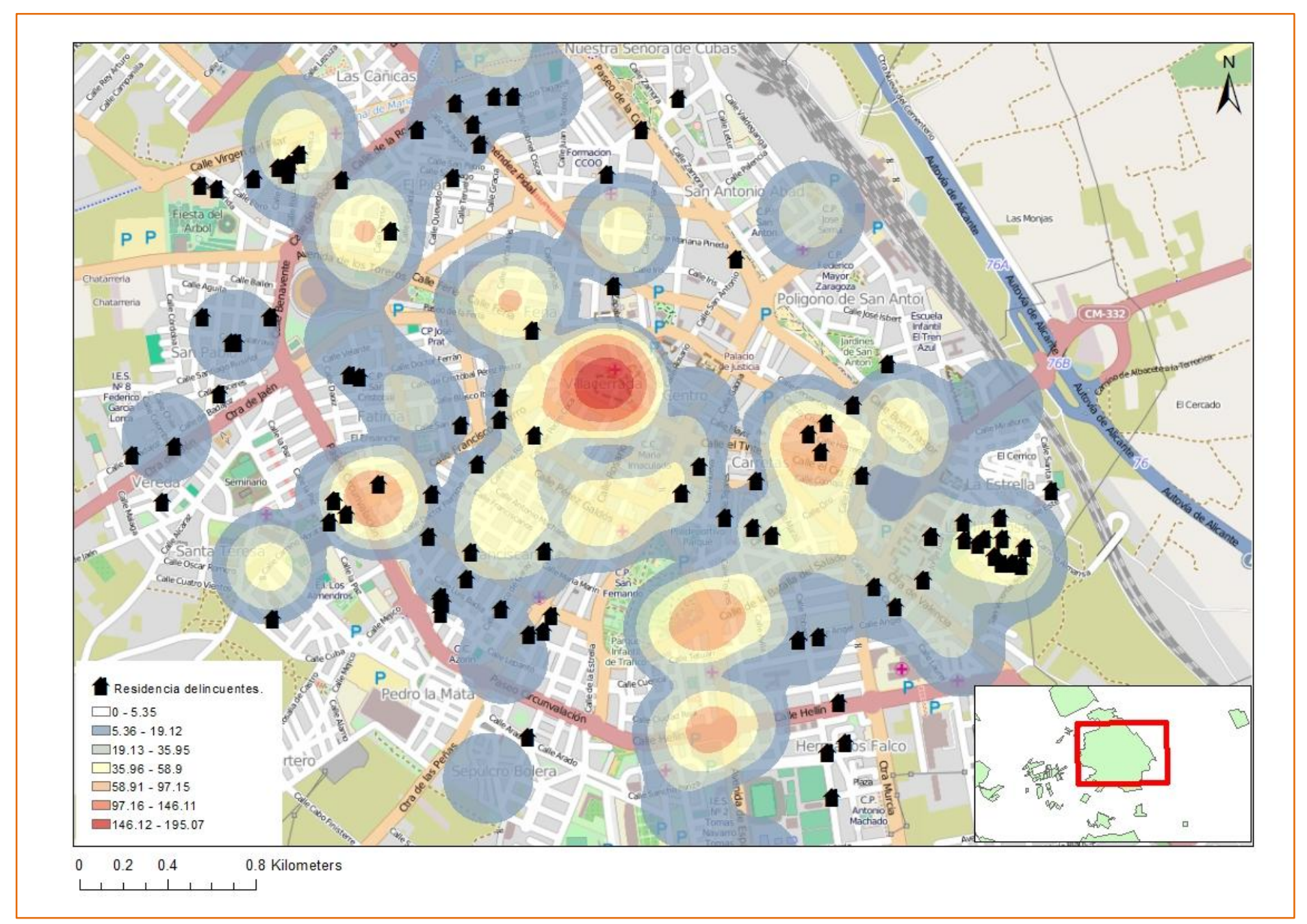


Como se puede apreciar en el mapa 1, la distribución espacial de la residencia de los jóvenes delincuentes parece indicar un patrón de concentración en zonas alejadas del centro de la ciudad (ubicado en el área central del mapa) que en algunos casos coinciden con zonas especialmente vulnerables como es el caso de los barrios de La Estrella y La Milagrosa ${ }^{9}$. Este patrón puede deberse, en parte, a aspectos como los precios de los inmuebles o incluso la existencia de edificios íntegramente dedicados a viviendas de protección oficial.

Así mismo, en gran parte de los casos se observa una correlación espacial entre el hogar de los delincuentes juveniles y las zonas con una mayor concentración delictiva (áreas rojas y amarillas), a excepción de dos de estas áreas ubicadas al Sur de la ciudad y el centro que a menudo suele representar una zona caliente en este tipo de análisis.

Para conocer el viaje individual que realiza cada delincuente, el mapa 2 muestra la distancia que cada sujeto recorrió desde su casa hasta el lugar de la conducta infractora $^{10}$.

\footnotetext{
${ }^{9}$ Análisis urbanístico de barrios vulnerables realizado por el Ministerio de Fomento. El informe completo está disponible en: http://habitat.aq.upm.es/bbvv/municipios/02003.pdf

${ }^{10}$ Señalar que por motivos de espacio y precisión en la representación, existen 3 observaciones no reflejadas en los mapas. Sus residencias o viajes al delito quedan fuera de los límites de la representación.
} 
Mapa 2. Desplazamientos (delitos contra el patrimonio y contra las personas)

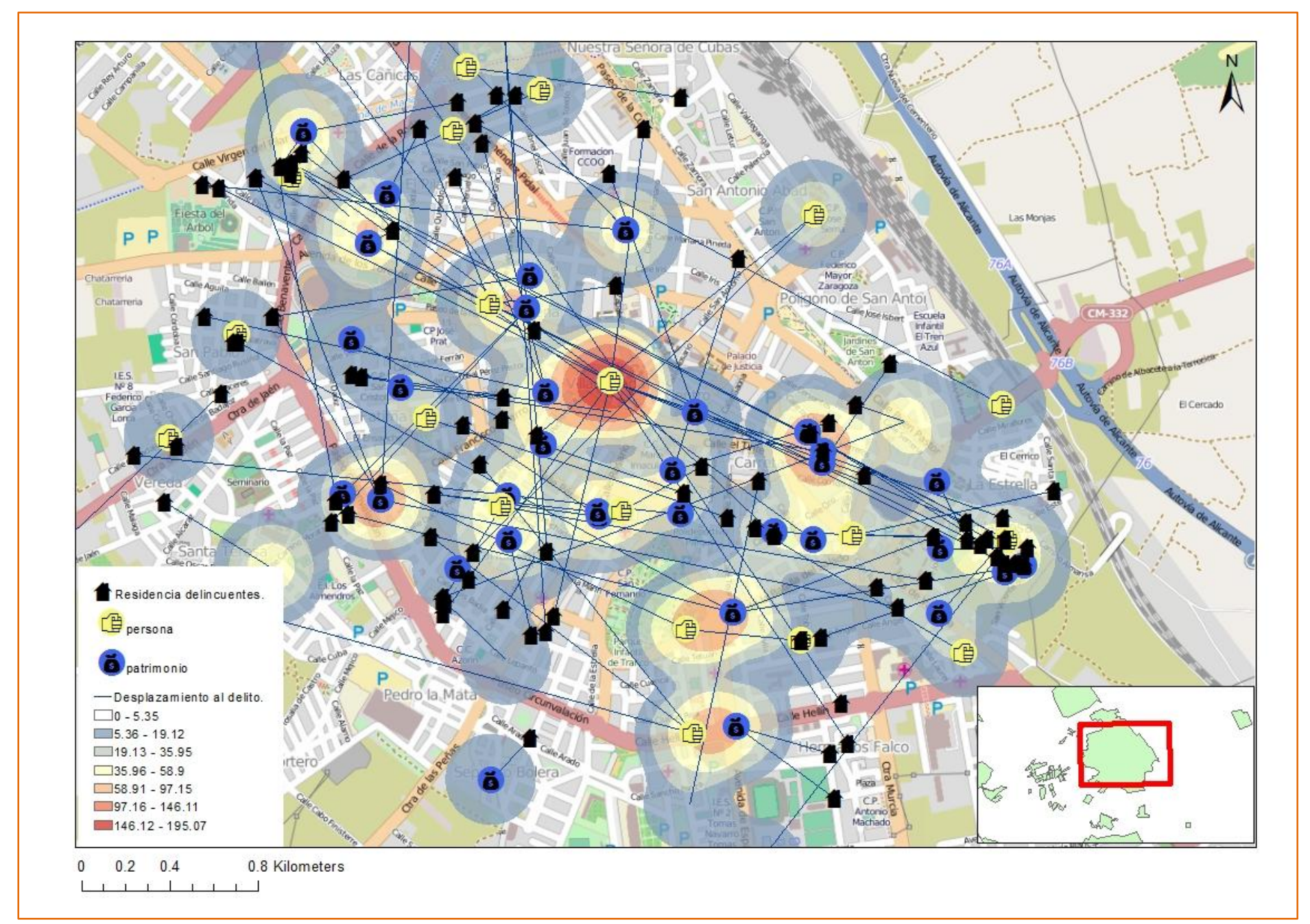

Revista Española de Investigación Criminológica 
Tal y como se puede apreciar, debido a la gran cantidad de desplazamientos representados en el mapa 2, las conclusiones que se pueden extraer son limitadas. No obstante, sí parece apreciarse que existen desplazamientos prácticamente por toda la ciudad, algunos de ellos bastante largos si se tiene en cuenta que el área metropolitana de la ciudad tampoco es grande. Así, los delincuentes que viven en zonas de concentración de delincuentes juveniles en el Este y el Oeste de la ciudad se desplazan por toda la ciudad, llegando incluso en ocasiones a los barrios dónde viven otros delincuentes o a sus áreas limítrofes.

Dado que la simple visualización de mapas no puede suponer una confirmación de los patrones, para profundizar en las características de los trayectos realizados por los delincuentes juveniles hasta el lugar del hecho delictivo se ha calculado la distancia que hay entre ambos puntos (origen y destino). Si se observan los resultados de la tabla 1 , se puede comprobar que el delincuente juvenil se desplaza una distancia media de 1.016,2 metros. No obstante, como la distribución de la muestra incumple el supuesto de normalidad, se ha tomado la mediana como valor de referencia (que es equivalente al percentil 50 de la tabla 1$)$.

A juzgar por la distribución que arrojan los percentiles, parece que sólo un 25\% de los delincuentes se desplazan más allá de los 1.374,35 metros. Exclusivamente un $9 \%$ de los delincuentes recorren entre los 2.000 y los 3.000 metros y hay un solo caso en el que el delincuente juvenil se desplazó 9.389 metros.

Tabla 1. Descriptivos de la distancia entre la casa del delincuente y el lugar del delito

\begin{tabular}{|c|c|c|c|c|c|c|c|}
\hline Variable & $\mathbf{X}$ & Desv. Est. & Mín & Máx & Perc. 25 & Perc. 50 & Perc. 75 \\
\hline Distancia & $1.016,2$ & $1.070,9$ & 14,7 & 9.389 & 398,2 & $\mathbf{7 7 0 , 9}$ & $1.374,3$ \\
\hline
\end{tabular}

Según los resultados de las pruebas de significación, se observa que por la mañana los hechos delictivos se cometen en espacios más cercanos al lugar de residencia, por la tarde es cuando se producen los desplazamientos más largos (todos más de 726 metros) y por la noche los hechos delictivos son cometidos en mayor 
medida en un radio comprendido entre los 430 y los 665 metros $\left(\chi^{2}=25,610\right.$; g.l. $=12$; $\mathrm{p} \leq 0,012)$.

Por otra parte, los desplazamientos más cortos se producen, como es lógico, en los casos de hechos delictivos de maltrato familiar, ya que suelen ser casos que se producen en el hogar de los protagonistas y en los delitos de lesiones que en su mayoría suponen casos de bullying. En estos casos los hechos suelen producirse en el radio de acción entre los 259 y los 430 metros. Los desplazamientos más largos (más de 1.824 metros) se producen en la comisión de hechos delictivos de robo en casa habitada; mientras que la gran mayoría de hechos delictivos juveniles (robos con violencia, daños y hurto) se producen en un radio de acción entre los 431 y los 1.823 metros $\left(\chi^{2}=121,120 ;\right.$ g.l. $\left.=78 ; \mathrm{p} \leq 0,001\right)$.

Así mismo, los resultados también han permitido comprobar que los hechos delictivos que se cometen en solitario lo son en un radio de acción que no supera los 400 metros y los hechos delictivos cometidos en compañía de otros menores se cometen en mayor medida entre los 432 y los 665 metros $\left(\chi^{2}=13,186\right.$; g.1. $\left.=6 ; p \leq 0,040\right)$.

Por último, también ha sido posible observar que cuando los hechos delictivos son cometidos sobre otros menores el desplazamiento es mayor que en relación a los cometidos sobre mayores de edad. También existe una distancia muy larga cuando el hecho delictivo es cometido sobre una persona jurídica, normalmente se trata de hurtos cometidos en tiendas de grandes superficies $\left(\chi^{2}=39,615 ;\right.$ g.l. $\left.=18 ; p \leq 0,002\right)$.

\subsection{Análisis de regresión}

Con el objetivo de profundizar un poco más en el desplazamiento que realizan los jóvenes delincuentes de esta ciudad desde sus hogares hasta el lugar de comisión del hecho delictivo, se ha realizado un análisis de regresión para valorar qué aspectos pueden predecir que el delincuente se desplace más o menos para cometer la conducta delictiva. En concreto se ha realizado un análisis de regresión lineal múltiple por pasos 
sucesivos, para tener en cuenta únicamente las variables que contribuyen al modelo de forma estadísticamente significativa ${ }^{11}$.

Tabla 2. Regresión lineal múltiple por pasos sucesivos

\begin{tabular}{|l|c|c|}
\hline \multicolumn{1}{|c|}{ Variables predictoras } & $\mathbf{B}^{\mathbf{a}}$ & $\boldsymbol{\beta}$ \\
\hline Tarde & 520,686 &, $243^{* *}$ \\
\hline $\mathrm{R}^{2}$ corregida $=, 051$ & 545,144 &, $255^{* *}$ \\
\hline Tarde & $-440,816$ &,$- 204^{*}$ \\
\hline Vía Pública & & \\
\hline $\mathrm{R}^{2}$ corregida $=, 084$ & & \\
\hline
\end{tabular}

* Probabilidad $<0,05 ; * *$ Probabilidad $<0,01$

Si se observan los resultados de la Tabla 2, inicialmente la ecuación de regresión introduce una única variable predictora, la tarde. Esta variable toma valor 1 si el hecho delictivo ha tenido lugar de 15:00 a 23:00 horas y 0 de lo contrario. El coeficiente estandarizado positivo $(\beta=, 243)$ indica que cuando el hecho delictivo se comete en la franja horaria de la tarde, los delincuentes juveniles se desplazan una mayor distancia, de media, 520 metros adicionales. En un paso posterior la ecuación introduce junto a la tarde, la variable vía pública. Esta variable también es una variable dicótoma que toma valor 1 si el delito se ha cometido en la vía pública y 0 de lo contrario. En este caso, a juzgar por el signo negativo del coeficiente $(\beta=-, 204)$ cuando el hecho delictivo se comete en la calle, el delincuente juvenil se desplaza una distancia menor, de media, 545 metros menos. De tal manera que, a pesar de haber tenido en cuenta distintas variables que podían aportar algo más de información sobre el desplazamiento que realizan los adolescentes; en realidad, sólo dos variables parecen tener un peso específico más importante. No obstante, y a juzgar por el porcentaje de varianza explicada de ambos pasos, un $5,1 \%$ en el primer paso, y un $8,4 \%$ en el segundo, el

\footnotetext{
${ }^{11}$ Con este método sólo se incorporan al modelo aquellas variables cuyos coeficientes de regresión parciales son significativamente distintos de 0 , con un nivel de significación del 5\%. La introducción de las variables, se hace de forma sucesiva eliminando de la regresión aquellas variables que no son estadísticamente significativas en la explicación de la distancia recorrida.
} 
tamaño del efecto es pequeño (Cohen, 1998), por lo que la capacidad predictiva de estas variables es limitada.

\section{Discusión y conclusiones}

Los resultados del análisis permiten realizar una valoración general de cómo influyen la morfología de la ciudad y los estilos de vida juveniles en la generación de puntos de concentración de delincuencia juvenil.

\subsection{Influencia de la morfología de la ciudad en las concentraciones de} delincuencia juvenil

El análisis exploratorio de los datos espaciales ha mostrado patrones de concentración de los delitos juveniles y de las viviendas de estos delincuentes en determinadas zonas de la ciudad. Además, en una parte importante de los casos se ha observado la existencia de una correlación espacial entre algunas de las áreas donde residen los

delincuentes y la concentración de sucesos delictivos. Siguiendo a Brantingham y Brantingham (1995) este comportamiento espacial podría estar relacionado con la existencia de ambientes que actúan como generadores, atrayentes y neutros respecto al delito.

Concretamente la distribución espacial de los delitos y las viviendas de los delincuentes juveniles permite diferenciar tres zonas con distintos patrones de agrupación, que a continuación se analizan:

a. Zonas donde se concentra un volumen importante de delitos pero no residen delincuentes.

En este sentido destacan dos áreas de hotspots (ver mapa 1): el centro de la ciudad (sombreada en color rojo intenso) y una arteria principal de Albacete ubicada al Sur (dos manchas rojas de un color algo menos intenso). 
La zona centro se caracteriza por albergar el principal núcleo comercial de la ciudad de Albacete, con múltiples tiendas, centros comerciales, cafeterías y bares. Además, en las inmediaciones se encuentran dos colegios públicos, y una plaza que es un punto de reunión habitual de grupos de jóvenes.

Por su parte, en la zona de la arteria principal del sur de la ciudad destacan dos hotspots, uno en una zona generalmente muy transitada, plagada de bares y cafeterías, donde además se encuentran varios centros escolares, un gran centro comercial y el Estadio de fútbol Carlos Belmonte; y otro a la altura del parque Abelardo Sánchez. donde está situado un Instituto de Educación Secundaria (en adelante IES) en el que suelen darse grandes concentraciones de jóvenes tanto en momentos previos como posteriores a las clases.

Todas estas zonas son ricas en objetivos, no solo por la concentración de establecimientos comerciales, centros escolares, establecimientos de ocio y atractivos turísticos; además porque a menudo congregan un gran volumen de personas por motivos, escolares, laborales, comerciales, de ocio, etc. Por ello, atendiendo a lo señalado por los Brantingham (1995) una parte importante de estos lugares parecen estar actuando como generadores de la delincuencia, en la medida en que reúnen a mucha gente que se desplaza hasta allí por motivos ajenos a cualquier motivación delictiva, como puede ser acudir a clase, hacer compras, ver un partido de futbol, etc.; y en la interacción entre diferentes individuos que comparten un mismo espacio el ambiente propicia oportunidades delictivas lo suficientemente tentadoras.

No obstante, en este caso no es posible hablar de lugares puramente generadores puesto que es muy probable que algunos también estén funcionando como atrayentes del delito, por ejemplo, en aquellos casos de jóvenes ultras que acuden a las inmediaciones del Estadio de futbol con la intención de buscar pelea, o el que se desplaza a robar hasta alguna de las tiendas situadas en la zona centro porque sabe que las medidas de seguridad son poco efectivas, etc.

En definitiva, teniendo en cuenta que ninguno de los hotspots analizados anteriormente coincide con los lugares donde viven los delincuentes, lo que sí parece confirmar el análisis de los datos espaciales es que los delincuentes juveniles se desplazan a estas zonas de la ciudad, en algunos casos guiados por una motivación 
delictiva expresa, y en otros, es a su paso por la zona cuando surge la oportunidad fruto de las condiciones ambientales.

b. Zonas donde viven delincuentes y registran un volumen considerable de delitos.

A tenor de los resultados obtenidos se observa que en Albacete los jóvenes delincuentes residen principalmente en zonas distanciadas del centro de la ciudad que en su mayoría, en concordancia con lo apuntado por Ocáriz, Vozmediano y Germán (2011), coinciden con barrios de un perfil socioeconómico bajo. En efecto algunos de estos infractores juveniles viven en zonas concretas de barrios como La Estrella-La Milagrosa, Hermanos Falcó, Santa Teresa de Jesús, El Pilar, Industria, o Colegio Santo Ángel caracterizadas por una especial vulnerabilidad social ${ }^{12}$ en donde los jóvenes acumulan un número importante de factores de riesgo asociados a la delincuencia.

A pesar de no asemejarse morfológicamente la estructura urbana de Albacete al modelo concéntrico planteado por Burguess (1967), cualitativamente dichos espacios donde residen los jóvenes delincuentes, muestran características similares a lo que este autor denomina zonas de transición. En este sentido, aspectos como la degradación arquitectónica, la rotación continuada de población itinerante no estable en la zona, la inestabilidad familiar, o la falta de cohesión social y vecinales ${ }^{13}$, podrían repercutir en un control social informal escaso y poco eficaz en el barrio, lo cual no garantiza la correcta supervisión del comportamiento de los jóvenes generando el caldo de cultivo idóneo para el desarrollo de conductas delictivas (Law y Quick, 2013; Wikström y Loeber, 2000). En general, en este tipo de zonas caracterizadas por un control social débil y un bajo nivel socioeconómico aumenta la probabilidad de la comisión de delitos violentos, pues el significado de identidad y pertenencia que otorgan los jóvenes al barrio donde viven es un factor importante para la conformación de bandas juveniles o grupos juveniles violentos ${ }^{14}$ (Kim LaGrange y Willis, 2013).

\footnotetext{
${ }^{12}$ Análisis urbanístico de barrios vulnerables realizado por el Ministerio de Fomento (2003). El informe completo está disponible en: http://habitat.aq.upm.es/bbvv/municipios/02003.pdf

${ }^{13}$ Plan para la integración social del municipio de Albacete. Excmo. Ayuntamiento de Albacete (2012). Disponible en: http://www.albacete.es/es/por-temas/servicios sociales/documentos/plan-para-laintegracion-social-del-municipio-de-albacete-2012-2014

${ }^{14}$ Como ha señalado Eurogang el fenómeno de las bandas juveniles no es frecuente en las ciudades europeas donde lo que se observa en mayor medida son la conformación de grupos de jóvenes antisociales que manifiestan un comportamiento delictivo (Medina, 2011).
} 
Tal y como ilustra el mapa 1 algunos barrios donde reside un importante volumen de delincuentes juveniles también registra una cantidad considerable de delitos. Principalmente esta tendencia se observa en cuatro zonas: en La Milagrosa (situada al Este-Sureste de la ciudad) concretamente en la plaza Tomás Navarro Tomás ubicada en el barrio denominado Las 600, en El pilar (al Noroeste), en Santa Teresa de Jesús - Fátima (al Suroeste), y en Carretas (al Este, aproximándose al centro).

En su mayoría estos lugares parecen estar funcionando como ambientes atrayentes del delito, pues son áreas residenciales por lo general de viviendas de protección oficial o de bajo coste, que no suelen concentrar aglomeraciones de gente ni atraer a personas ajenas al barrio para realizar actividades que puedan derivar en oportunidades delictivas. Algunas de estas zonas además de estar situadas en la periferia están fuertemente estigmatizadas socialmente como es el barrio de Las 600, lo que hace que la población general no se plantee adentrarse por el miedo a la victimización.

En ciertos puntos es habitual la venta de droga, objetos robados y otros ilícitos, lo cual atrae la actividad delictiva. Además, todos ellos tienen el denominador común de ser espacios degradados física y socialmente, lo que en concordancia con la teoría de las ventanas rotas facilita la propagación del delito a modo de contagio (Harcourt y Ludwing, 2006).

Por otra parte, se encuentran las zonas de Santa Teresa de Jesús -Fátima y Carretas, que pueden ser consideradas ambientes mixtos predominantemente generadores de delincuencia, pues albergan lugares como un Hospital y un IES, y la segunda, un colegio público. Lo cual lleva diariamente a muchas personas a desplazarse a estas zonas para ir a clase o para ser atendidos en el centro médico. Esto facilita la convergencia espacio-temporal de posibles víctimas y delincuentes (entre ellos los que viven en el barrio).

Teniendo en cuenta las cualidades atrayentes y generadoras de estos barrios, es preciso señalar que esta correlación espacial observada entre zonas donde viven los delincuentes juveniles y zonas con una importante concentración delictiva no sólo puede estar reflejando que sean los propios delincuentes que viven en barrio los que delinquen, pues como señala Schaefer (2012) los jóvenes infractores son propensos a desplazarse a barrios socialmente similares a los suyos. 
c. Zonas donde viven delincuentes pero apenas se registran delitos.

Por último, se han observado lugares donde se agrupan los domicilios de los delincuentes juveniles pero apenas suceden delitos (mayoritariamente sombreadas de color azul en el mapa 1). En este sentido destacan las zonas de: Industria (al NoroesteNorte), Hermanos Falcó (al Sur-Sureste) principalmente en el barrio de Las $300^{15}$, Fátima y Franciscanos a (al Centro-Suroeste), San Pablo (al Oeste), y un área concreta entre la zona Centro y Carretas (Centro-Sureste). En contraste con las zonas analizadas en el sub-epígrafe anterior, donde además de concentrarse la residencia de delincuentes juveniles se registra un volumen considerable de hechos delictivos, en éstas no se observa una relación espacial importante entre ambos fenómenos.

La pregunta entonces es por qué a pesar de vivir un volumen considerable de delincuentes en estas zonas apenas se registran hechos delictivos. Atendiendo a definición de las zonas neutras respecto al delito de Brantingham y Brantingham (1995) la respuesta puede estar relacionada con que estos lugares estén actuando como zonas neutras respecto al delito. Es decir, a diferencia de los lugares analizados en el anterior apartado, estas son áreas residenciales de la ciudad de Albacete que por lo general no parecen contener características ni atrayentes ni generadoras de delincuencia. Por tanto, son consideradas neutras porque ni atraen delincuentes con la intención de cometer un delito en particular, ni generan delitos mediante la creación de oportunidades delictivas demasiado tentadoras para resistirse.

Sin embargo, sombreado de azul en el mapa 1 se observa que en estos barrios, aunque muy baja, también existe una pequeña concentración de delitos. En este sentido, siguiendo lo apuntado por Brantingham y Brantingham (1995) parece muy probable que de estos delitos sean responsables los delincuentes juveniles residentes en el barrio. Pues estas zonas, al no poseer características ni atrayentes ni generadoras, apenas deberían congregan a personas (delincuentes o no) provenientes de otros barrios. Por tanto, las oportunidades y las posibilidades de que sucedan delitos puede ser menor que el resto de zonas analizadas.

\footnotetext{
${ }^{15}$ Esta zona de viviendas es fruto de una reubicación de vecinos del barrio de Las 600 (La Milagrosa), concretamente de la Plaza Tomás Navarro Tomás, una zona especialmente degradada socialmente.
} 
Así mismo, es probable que los delincuentes juveniles residentes en estos barrios con una baja concentración delictiva también cometan sus delitos cuando se desplazan a otros lugares, y probablemente sean responsables de las concentraciones delictivas en el centro de la ciudad y otras áreas relativamente cercanas a sus barrios.

En este sentido, en concordancia con la teoría de las actividades rutinarias (Cohen y Felson, 1979) y del patrón delictivo (Brantingham y Brantingham, 1991) el hecho de que estos delincuentes cometan delitos fuera o en los límites de sus barrios podría deberse a que diariamente se desplazan a otros de sus nodos de actividad que actúan como generadores del delito, como pueden ser establecimientos comerciales y de ocio o la escuela/instituto (que puede estar cerca pero no en el mismo barrio); y es allí o en el camino, dónde y cuándo surgen la mayor parte de oportunidades delictivas. Así mismo, en el caso de delitos premeditados (como puedan ser robos, hurtos, venta de droga, etc.) es muy probable que estos delincuentes se desplacen a otras zonas de las que se ha hablado anteriormente, que actúan como atrayentes del delito. En este caso el área cercana a la casa de los delincuentes sería el área de seguridad donde el delincuente no actúa por temor a ser reconocido.

En definitiva, los resultados del análisis sugieren que la delincuencia juvenil se aglutina fundamentalmente en los espacios donde los jóvenes pasan la mayor parte del tiempo, en sus barrios o en los de otros jóvenes antisociales que viven en barrios con unas características muy similares a las suyas, y en las zonas donde acuden a practicar sus actividades de ocio, que por sus características son espacios con muchos objetivos atractivos para los chicos y en donde la gran cantidad de gente que suele aglutinarse en los mismos, puede hacer que haya más probabilidad de encontrar víctimas propicias.

\subsection{Influencia del estilo de vida de los jóvenes en la concentración de} actividad delictiva juvenil

Atendiendo a lo expuesto en el sub-epígrafe anterior se hace patente que gran parte de la explicación de los puntos de concentración de delincuencia juvenil podría encontrarse en la comprensión de los estilos de vida juvenil. En este sentido, se sabe que las actividades de rutina que realizan los jóvenes están restringidas a lugares muy concretos 
debido a su aún limitado espacio de conciencia y a un menor acceso a vehículos de motor (Weisburd, Morris y Groff, 2009).

Los resultados obtenidos, en concordancia con otras investigaciones (Andresen, Frank y Felson, 2013; Drawve, Walker y Felson, 2014; Phillips, 1980; Snook, 2004; Wiles y Costello, 2000) sugieren que la distancia recorrida por los delincuentes juveniles en la ciudad de Albacete por lo general es corta, 770,9 metros, más aún si cabe en el caso de los delitos violentos, que en su mayoría no superan los 430 metros.

Según la literatura consultada, junto con el hogar uno de los principales nodos de actividad juvenil es la escuela/instituto, por ser donde pasan diariamente gran parte de su tiempo. Por ello, es en las instalaciones de los centros educativos, en las inmediaciones, o en el camino tomado para ir a casa, donde surgen la mayor parte de oportunidades delictivas (Drawve, Walkera y Felson, 2014; Jacob y Lefgren, 2003; Weisburd, Morris y Groff, 2009). De manera consistente con los hallazgos realizados por Drawve, Walker y Felson (2014) y Weisburd, Morris y Groff (2009) nuestros datos muestran que la mayor parte de los puntos calientes de la delincuencia juvenil se encuentran en lugares donde hay centros educativos cerca. Concretamente, en el punto caliente central se encuentran dos colegios públicos, en los puntos calientes de la zona Sur están ubicados dos IES, así como un colegio público; por su parte las concentraciones delictivas situadas al Suroeste de la ciudad coinciden con un área donde se encuentra un IES, y en las inmediaciones del hotspot de la zona Centro-Sur hay otro colegio público.

Así mismo, se ha constatado que la mañana es la franja horaria cuando se cometen los delitos en espacios más cercanos al lugar de residencia. Esto, parece lógico desde el punto de vista de las actividades rutinarias (Cohen y Felson, 1979) teniendo en cuenta que, por lo general,

los centros educativos a los que acuden los menores se encuentran en el propio barrio o en áreas cercanas; y dependiendo de la hora los menores están en casa, en el centro educativo o en un área comprendida entre ambos puntos. Concretamente, en horario matinal los chicos cometen delitos de agresiones en el ámbito escolar, y surgen los episodios de violencia familiar en el hogar durante la hora de la comida.

Resultados que refuerzan la tesis planteada por Bichler, Christie-Merall y Sechrest (2011) y Jacob y Lefgren (2003) quienes señalan que estos patrones delictivos 
temporales son indicativos de la influencia de los horarios escolares en la configuración de las actividades rutinarias de la juventud. Reflejo de ello es que los delitos violentos aumentan de forma constante durante el horario escolar, con un pico espectacular en el momento en que finaliza dicha actividad entre las 15:00 y 16:00 horas. Según estos autores, a pesar de la percepción general de que las escuelas constituyen instrumentos de contención del delito, al mantener a los jóvenes ocupados y bajo la supervisión de profesionales, los jóvenes encuentran allí o en el trayecto entre el hogar y la escuela suficientes oportunidades para participar en una conducta delictiva o para ser victimizado.

La explicación que ofrecen Jacob y Lefgren (2003) al respecto es que la concentración geográfica de los menores en un mismo espacio incrementa el número de interacciones potencialmente conflictivas. En la medida en que la delincuencia juvenil violenta depende al menos en parte de tales interacciones, la confluencia en los centros educativos contribuye a elevar el nivel de delitos violentos. Además, se sabe que el efecto generador de delincuencia violenta de la escuela o el instituto puede propagarse a otros lugares y momentos temporales, pues un conflicto iniciado allí puede continuar o encontrar desenlace, por ejemplo, a la salida de clase, en las inmediaciones del centro escolar o al encontrarse los jóvenes durante la tarde o el fin de semana en lugares de ocio.

Por otra parte, de acuerdo con De Coster, Heimer y Wittrock (2006), el hecho de que los delitos violentos sean los que suceden en un radio más cercano a la casa o el barrio del agresor, en algunos casos también puede deberse al fuerte vínculo entre delincuencia violenta y aspectos tales como la exposición a elementos ambientales criminógenos, la desventaja social de familias y comunidades, o lazos familiares debilitados. Especialmente en el caso de las minorías y las familias socioeconómicamente más desfavorecidas quienes tienen muy limitadas sus opciones residenciales y se ven relegadas a vivir en determinadas zonas que por sus características están relacionadas con una mayor probabilidad de violencia juvenil.

A diferencia de lo que ocurre con las agresiones, que parecen estar relacionadas espacial y temporalmente con una de las principales actividades rutinarias de los jóvenes en horario de mañana como es ir a la escuela/instituto, los delitos contra el patrimonio apenas muestran incidencia en esas zonas y momentos del día. En este 
sentido, como apuntan Drawve, Walkera y Felson (2014), Groff (2005), Jacob y Lefgren (2003), Weisburd, Morris y Groff (2009), es coincidiendo con su tiempo libre, en el momento en que los jóvenes se desplazan a otros lugares comerciales o de ocio, cuando se incrementa esta otra tipología delictiva.

En la misma línea, nuestros resultados señalan que por la tarde es cuando se producen los desplazamientos más largos (todos más de 726 metros), coincidiendo con los hallazgos de Drawve, Walkera y Felson (2014) principalmente para cometer delitos de hurto en las zonas comerciales del centro y de la periferia en los grandes centros de consumo y los delitos de robo con violencia sobre otros menores. Ésta es de hecho la única variable que es capaz de predecir un mayor desplazamiento para la comisión del delito. Probablemente, y a juzgar por donde se han cometido estos delitos, esta mayor distancia esté relacionada con las dinámicas que los jóvenes llevan a cabo en sus horas de ocio durante la tarde, en concreto con las oportunidades que surgen en espacios de convergencia con las víctimas, relacionados con sus nodos de actividad no delictiva, como pueden ser, ir a los parques, cines, restaurantes de comida rápida, tiendas, bares, instalaciones deportivas, etc. (Bichler, Christie-Merall y Sechrest, 2011; Drawve, Walkera y Felson, 2014; Weisburd, Morris y Groff, 2009). A diferencia de la mañana, los jóvenes gozan de mayor libertad para su movilidad por las tardes, pues no deben acudir a la escuela o el instituto, y es en torno a sus espacios de conciencia donde pueden surgir las oportunidades delictivas (Schaefer, 2012).

Por la noche, sin embargo, la distancia disminuye y los delitos son cometidos más cerca del perímetro de seguridad en torno a la casa del joven, en concreto en un radio comprendido entre los 430 metros y los 665 . Atendiendo a la distancia recorrida por los menores durante esta franja horaria, se observa que los delitos son cometidos principalmente dentro del mismo barrio. Los delitos más comunes son los daños, especialmente, sobre coches y algunos robos sobre zonas con menos vigilancia o sobre víctimas (adultas) a las que la escasa presencia de otras personas en las calles las hace más vulnerables. La noche, debido a una menor presencia de personas en las calles y a la ausencia de luz, contribuye a un mayor anonimato y por tanto el temor a ser reconocido en las cercanías del entorno habitual, disminuye.

En este caso, el incremento de oportunidades delictivas parece estar relacionado con uno de los supuestos planteados por Felson y Clarke (1998), el descenso del nivel 
de vigilancia, que ayuda a los delincuentes a ser más eficientes en su labor. Ya sea por una peor iluminación, o por la falta de control social informal característica del tipo de barrio donde residen principalmente los delincuentes juveniles en la ciudad de Albacete, la noche propicia el entorno adecuado para delinquir sin necesidad apenas de desplazarse.

En definitiva, el análisis de los patrones en el movimiento de los delincuentes juveniles parece indicar que las actividades rutinarias de los jóvenes hacen que la convergencia entre delincuentes y víctimas/objetivos sea más probable en unos lugares que en otros.

\subsection{Implicaciones}

El presente trabajo, a pesar de ser una primera aproximación exploratoria al comportamiento espacial del fenómeno, creemos que brinda información valiosa respecto a la naturaleza y la motivación de la delincuencia juvenil. Concretamente, nuestro análisis sugiere que en aquellos lugares y momentos en los que los menores no están supervisados son más propensos a involucrarse en ciertas conductas delictivas contra la propiedad. Así mismo, parece evidenciar que el grado de interacción entre jóvenes juega un papel significativo en el nivel de violencia, lo que destaca la naturaleza social de la violencia juvenil.

Estos hallazgos pueden resultar de utilidad para las instituciones locales como el ayuntamiento, la policía y los servicios sociales de manera que prestando atención a las dinámicas descritas, es posible articular estrategias de prevención e intervención más eficientes y eficaces en lugares concretos de la ciudad de Albacete. Por ejemplo, en aquellos barrios con mayor concentración de delincuentes juveniles residiendo en la zona, el diseño de programas preventivos de actividades de ocio y tiempo libre en horario extraescolar, durante la tarde o la noche, puede ser de gran utilidad para mantener a los jóvenes ocupados durante las horas en las que, por lo general, se desplazan a otros lugares para cometer principalmente delitos contra el patrimonio $\mathrm{u}$ otros delitos oportunistas. Sin embargo, teniendo en cuenta que durante este tipo de actividades aumenta la concentración de jóvenes en lugares determinados, también se corre el riesgo de aumentar el número de delitos violentos fruto de esa interacción. Por 
ello, como apuntan Jacob y Lefgren (2003), las autoridades pueden considerar el diseño de programas más pequeños, basados en el vecindario, que permitan controlar las interacciones e incorporen estrategias de resolución de conflictos. También pueden ser útiles otro tipo de programas orientados a generar vínculos y redes vecinales que permitan un mayor control social informal dentro del barrio. Así mismo, los resultados obtenidos también son útiles de cara a articular otras estrategias de intervención más recurrentes como es el aumento de la vigilancia policial en aquellas zonas que se ha comprobado que tienden a agrupar un mayor número de delitos cometidos por jóvenes.

\subsection{Limitaciones e investigación futura}

A pesar de lo expuesto, hay que tener en cuenta que esta investigación no ha estado exenta de limitaciones. La principal deficiencia ha sido, al igual que en otras muchas de las investigaciones de este tipo, tomar la casa del delincuente como el origen del trayecto, pues en concordancia con la teoría de las actividades rutinarias siempre cabe la posibilidad de que el desplazamiento tenga su inicio en otro lugar como establecimientos de ocio, centros educativos, el lugar de trabajo, etc. (Andresen, Frank y Felson, 2014; Townsley y Sidebottom, 2010; Wiles y Costello, 2000). De ser así, en esta investigación en un número considerable de los casos analizados la distancia del desplazamiento basada en el domicilio sería probablemente incorrecta. El problema es que los datos oficiales por motivos de operatividad, por lo general, son reducidos y sólo recogen aspectos como la localización del domicilio del delincuente y la ubicación del delito. Una alternativa para corregir este problema sería realizar entrevistas a los delincuentes para conocer datos específicos. El reducido tamaño muestral también ha sido un factor limitador pues no se contaba con casos suficientes para ciertos delitos y edades.

Además, futuras investigaciones no solo deberán tratar de paliar estas limitaciones, sino que sería importante que pudieran confirmar los resultados obtenidos en otros contextos nacionales, y analizar cuestiones como las variaciones en la distancia recorrida en función de variables relevantes como la edad o la tipología delictiva. También, incorporar al análisis otros aspectos del trayecto como por ejemplo: la 
motivación del delincuente, dónde tiene intención de llegar, qué camino toma, cuánto tiempo dura el trayecto, la dirección en la que se desplaza, o el modo de desplazarse.

En lo que se refiere a esta última cuestión, el modo de desplazarse hasta el lugar del delito, son muchos de los trabajos que sugieren la importancia de esta variable, pues un menor acceso a vehículos a motor parece limitar los desplazamientos de los delincuentes juveniles. Sin embargo, en el caso de ciudades pequeñas como es el caso de Albacete, podría no ser tan importante como en otras más extensas. Al ser un una localidad de escasas dimensiones, donde no hay grandes distancias, es posible recorrer fácilmente la ciudad de un extremo a otro andando. Además en este caso la orografía favorece el uso de vehículos de bajo coste y que no precisan permiso de circulación como la bicicleta, monopatines, etc.

Por último, para saber más acerca de cómo las actividades rutinarias de los adolescentes dan forma a la capacidad criminógena de algunos lugares, de acuerdo con lo señalado por Bichler, Christie-Merall y Sechrest (2011) podría resultar de interés prestar atención a las dinámicas de actividad no delictiva de los delincuentes juveniles, analizando sus nodos de actividad cotidiana y las rutas tomadas.

\section{Agradecimientos}

Nos gustaría agradecer la ayuda prestada por parte del personal que trabaja en el Instituto de Desarrollo Regional de la Universidad de Castilla-La Mancha - TERYSOS, en especial a Javier Sánchez y David Cifuentes. Así mismo, también queremos agradecer a los revisores anónimos y al editor de la REIC los perspicaces comentarios realizados al documento que indudablemente han ayudado a mejorar su calidad científica.

\section{Financiación}

Este trabajo se ha realizado con una ayuda del Plan Nacional I+D+i del Ministerio de Economía y Competitividad, "Análisis criminológico de la justicia penal en España. Una profundización sobre el proceso de producción de datos oficiales y sobre la eficacia del sistema de justicia” (DER2011-28769).

\section{Referencias}

Andresen, M.A., Frank, R. y Felson, M. (2014). Age and the distance to crime. Criminology \& Criminal Justice, 14 (3), 314-333. 
Ayuntamiento de Albacete (2012). Plan para la integración social del municipio de Albacete. Disponible en: http://www.albacete.es/es/portemas/servicios_sociales/documentos/plan-para-la-integracion-social-delmunicipio-de-albacete-2012-2014

Bernasco, W. (2014). Crime Journeys: Patterns of Offender Mobility. En M. Tonry (Ed). Oxford Handbooks Online in Criminology and Criminal Justice. Oxford: Oxford University Press.

Bichler, G., Christie-Merrall, J. y Sechrest, D. (2011). Examining juvenile delinquency within activity space: Building a context for offender travel patterns. Journal of Research in Crime and Delinquency, 48(3), 472-506.

Block, R., Galary, A. y Brice, D. (2007). The journey to crime: victims and offenders converge in violent index offences in Chicago. Security Journal, 20, 123-137.

Brantingham, P. y Brantingham, P. (1995). Criminality of Place: Crime Generators and Crime Attractors. European Journal on Criminal Policy and Research, 3(3), 526.

Brantingham, P. y Brantingham, P. (1993). Nodes, Paths and Edges: Considerations on the Complexity of Crime and the Physical Environment. Journal of Environmental Psychology, 13, 3-28.

Brantingham, P. y Brantingham, P. (1991). Environmental Criminology. Prospect Heights: Waveland Press.

Burguess, E.W. (1967). The growth of the city: an introduction to a research project. Ardent Media.

Cohen, J. (1998). Statistical power analysis for the behavioral sciences. New York: Academic.

Cohen, L.E. y Felson, M. (1979). Social Change and Crime Rate Trends: A Routine Activity Approach. American Sociological Review, 44 (4), 588-608.

Cornish, D.B. y Clarke, R.V. (2008). The rational choice perspective. En R. Wortley y L. Mazerolle, Environmental Criminology and Crime Analysis. Portland: Willan Publishing.

Dávila, J.M. y Ponce, G. (1988). La distribución espacial de la delincuencia en el País Valenciano y su relación con algunas variables socioeconómicas, Investigaciones geográficas, 6, 187-205.

Drawve, G., Walker, J.T. y Felson, M. (2014). Juvenile offenders: an examination of distance-to-crime and crime clusters. Cartography and Geographic Information Science, 1-12. 
De Coster, S., Heimer, K. y Wittrock, S.M. (2006)._Neighborhood disadvantage, social capital, street context, and youth violence. The Sociological Quarterly, 47, 723753.

Felson, M. (2006). Crime and nature. Thousand Oaks: Sage Publications.

Felson, M. y Clarke, R.V. (1998). Opportunity Makes the Thief. Practical theory for crime prevention. Police Research Series, 98. Londres: Home Office.

Groff, E.R. (2005). The geography of juvenile crime place trajectories. Tesis doctoral inédita. Universidad de Maryland.

Harcourt, B.E. y Ludwing, J. (2006). Broken windows: new evidence from New York city and a five city Social Experiment. The University of Chicago Law Review, 73, 271-320.

Irene, Y.H. (2010). Where juvenile serious offenders live: A neighborhood analysis of Wayne Country, Michigan.Journal of Criminal Justice, 38, 207-215.

Jacob, B.A. y Lefgren, L. (2003). Are Idle Hands the Devil's Workshop? Incapacitation, Concentration and Juvenile Crime. The American Economic Review, 93 (5), 1560-1577.

Kent, J., Leitner, M. y Curtis, A. (2006). Evaluating the usefulness of functional distance measures when calibrating journey-to-crime distance decay functions. Computers Environment and Urban Systems, 30, 181-200.

Kim, S., LaGrange, R.L. y Willis, C.L. (2013). Place and Crime Integrating Sociology of Place and Environmental Criminology. Urban Affairs Review, 49(1), 141-155.

Law, J. y Quick, M. (2013). Exploring links between juvenile offenders and social disorganization at a large map scale: a Bayesian spatial modeling approach. Journal of Geographical Systems, 15(1), 89-113.

Levine, N. y Lee, P. (2009). Bayesian Journey-to-Crime Modeling of Juvenile and Adult Offenders by Gender in Manchester. Journal of Investigative Psychology and Offender Profiling, 6, 237-251.

Loeber, R., Farrington, D., y Redondo, S. (2011). La transición desde la delincuencia juvenil a la delincuencia adulta. Revista Española de Investigación criminológica, 9, 1-41.

Medina, J.J. (2011). Politicas y estrategias de prevención del delito y seguridad ciudadana. Madrid: Editorial Bdef.

Ministerio de Fomento (2003). Análisis urbanístico de barrios vulnerables en España. Albacete. Departamento Urbanística y Ordenación del Territorio IJH/ETSAM. 
Ocáriz, E., Vozmediano, L. y Germán, I. (2011). La variable "lugar de residencia" de los menores infractores: Relevancia y propuestas para su análisis geográfico. International E-Journal of Criminal Sciences, 1(4), 1-24.

Philips, P.D. (1980). Characteristics and typology of the journey to crime. En D.E. Georges-Abeyie y K.D. Harries (eds.), Crime: A spatial Perspective (Pp. 167180). Nueva York: Columbia University Press.

Schaefer, D.R. (2012). Youth co-offending networks: An investigation of social and spatial effects. Social networks, 34(1), 141-149.

Snook, B. (2004). Individual Differences in Distance Travelled by Serial Burglars. Journal of Investigative Psychology and Offender Profiling, 1,53-66.

Townsley, M. y Sidebottom, A. (2010). All Offenders are equal, but some are more equal than others: Variation in journeys to crime between offenders. Criminology, 48(3), 897-917.

Van Patten, I.T., McKeldin-Coner, J. y Cox, D. (2009). A Microspatial analysis of robbery: prospective hot spotting in a small city. Crime Mapping: A Journal of Research and Practice, 1 (1), 7-32.

Vozmediano, L. y San Juan, C. (2010). Criminología Ambiental. Ecología del Delito y de la Seguridad. Barcelona: Editorial UOC.

Waller, L.A. Gotway, C.A. (2004). Applied Spatial Statistics for Public Health Data. Hoboken NJ: Wiley.

Weisburd, D., Morris, N.A. y Groff, E.R. (2009). Hot Spots of Juvenile Crime: A Longitudinal Study of Arrest Incidents at Streets Segments in Seattle, Washington. Journal of Quantitative Criminology, 25, 443-467.

Wikström, P.H. y Loeber, R. (2000). Do disadvantaged neighborhoods cause welladjusted children to become adolescent delinquents? A study of male juvenile serious offending, individual risk and protective factors, and neighborhood context. Criminology, 38 (4), 1109-1142.

Wiles, P. y Costello, A. (2000). The "road to nowhere": the evidence for travelling criminals. Londres: Research, Development and Statistics Directorate, Home Office.

David Vázquez Morales es investigador contratado del Centro de Investigación en Criminología de la Universidad de Castilla-La Mancha. Es graduado en Trabajo Social y Máster en Criminología y Delincuencia Juvenil por la Universidad de Castilla-La Mancha. Sus principales líneas de investigación son: la confianza pública en el sistema de justicia y el comportamiento espacial de la delincuencia. 
Esther Fernández Molina es Profesora Contratado Doctor del Centro de Investigación en Criminología de la Universidad de Castilla-La Mancha y Secretaria Académica del Master en Criminología y Delincuencia Juvenil de esta universidad. Sus principales líneas de investigación son la justicia de menores, las actitudes hacia el castigo juvenil, opinión pública y delito y más recientemente ha trabajado en miedo al delito y confianza en las instituciones penales.

Simón Planells-Struse es candidato a doctor en economía e investigador del Instituto de Economía de Barcelona y docente de economía pública en la Universidad de Barcelona. Es profesor colaborador del centro Crímina y consultor en temas de delincuencia para los Mossos d'Esquadra y el ayuntamiento de Barcelona. Tras un período como investigador visitante junto a Luc Anselin en la Universidad Estatal de Arizona, ha centrado su investigación en el análisis espacial de la delincuencia. Sus publicaciones han aparecido en revistas como Crime and Delinquency, Contemporary Reading in Law and Social Justice, Regional and Economic Studies and The Encyclopedia of Crime and Punishment.

Mario Belmonte Mancebo es Ingeniero Agrícola y del Medio Rural, forma parte del grupo de Teledetección y Sistemas de Información Geográfica del Instituto Regional de Desarrollo de la Universidad de Castilla-La Mancha. 